\title{
Pruebas de detección del cáncer cervicouterino asociado al Virus del Papiloma Humano (VPH)
}

\author{
Justa Francisca Bermúdez Pérez, Cristiana Paola Cabezas Robelo, \\ Kenia Lizeth García Rosales, Silvia Marcela Gaitán Velásquez \\ Tutora: Msc. Martha Xiomara Guerrero
}

\section{RESUMEN}

El cáncer cervicouterino ocupa el segundo lugar en frecuencia en todo el mundo y es el principal en la mayoría de los países en vías de desarrollo, según la Organización Panamericana de la Salud (OPS). Se determinó las pruebas de detección del cáncer cérvico uterino, la frecuencia de cambios celulares del cérvix sospechosas, y asociadas al virus del papiloma humano. El estudio fué descriptivo de corte transversal en el Hospital Bertha Calderón Roque cuyo universo fueron 181 mujeres atendidas en consulta externa, la muestra fué 83(45.8\%) mujeres con PAP positivo y diagnosticadas con VPH. Según los resultados las preubas de diagnósticos utilizados fueron citológicos (PAP) y biopsia por conización mediante asa diatérmica con un $100 \%$. No se realizan métodos moleculares para la detección del virus. Los cambios morfológicos obtenidos a partir de citología cervical y biopsia fueron la lesión de bajo grado o NIC I con el 14\% detectado mediante colposcopia y para Condiloma un $11 \%$ a través de biopsia. Las lesiones escamosas de alto grado, se obtuvo un $33 \%$ para NIC III mediante biopsia por asa diatérmica. En el caso de ASCUS se detectaron en un $22 \%$ a través de PAP. Se observó que la mayor prevalencia de VPH fue en mujeres en las edades entre 19-48 años con un 70\%. En conclusión, los métodos de diagnóstico más utilizados son los citohistológicos, y la lesión escamosa de alto grado con mayor porcentaje fue el NIC III y observamos que las mujeres en edades jóvenes son las más afectadas.

Palabras claves: VPH, cáncer cervical, pruebas diagnósticas, ASCUS, NIC

\section{SUMMARY}

Cervical cancer is the second most common worldwide and is the leading in most developing countries, according to the Pan-American Health Organization (PAHO). We explored the diagnostic methods for detection of cervical cancer, and the frequency of suspicious cervical cell changes associated with human papilloma virus was determined. The study was descriptive of cross section at Bertha Calderon Roque Hospital. The universe was composed of 181 samples from women attending outpatient therapy. The sample consisted of 83 (45.8\%) women with positive PAP and diagnosed HPV. According to the results (PAP) and cone biopsy with diathermic loop were used as cytologic diagnoses technique with 100\%. Molecular methods for HPV detection were not performed. Morphological changes obtained from cervical cytology and biopsies were low-grade injury or CIN I( 14\%) detected by colposcopy and Condiloma (11\%) detected by biopsy. The high-grade squamous lesions were: CIN III (33\%) obtained by diathermic loop biopsy, regarding ASCUS (22\%) were detected in by PAP. We observed that the highest prevalence (70\%). of HPV was in women between 19-48 years old. In conclusion, the most widely diagnostic methods used for cervical cancer detection were the cytohistologies, and the high-grade 
squamous intraepithelial injury most frequent was the NIC III and the women in younger age groups were the most affected.

Keywords: HPV, cervical cancer, diagnostic methods, ASCUS, CIN

\section{INTRODUCCIÓN}

La infección por Virus del Papiloma Humano (VPH), es considerada actualmente como una infección de transmisión sexual (ITS) más frecuente en el mundo. La gran mayoría de estas infecciones son asintomáticas o subclínicas, pasan desapercibidas a no ser que se empleen métodos moleculares, para detectar fragmentos del genoma en las células infectadas (Dabancens, Ojeda. \& Prado, 2004).

El cáncer de cuello uterino es el tumor maligno más frecuente en las mujeres provenientes de los países en desarrollo y ocupa el tercer lugar en mortalidad relacionada con las neoplasias malignas en la población en general. Entre los métodos de diagnóstico del cáncer de cérvix más utilizados a nivel nacional son la citología cervical o examen del Papanicolaou, el cual es el método de elección y la forma más sencilla para la prevención oportuna de este.

La Organización Panamericana de la Salud (2013), publicó en su estrategia y plan de acción regional para la prevención y el control del cáncer cervicouterino en América y el caribe que cada año 71,862 nuevos casos son diagnosticados en el subcontinente y más de 32,000 afectadas fallecen en la región. En Nicaragua se diagnosticaron 6,200 casos nuevos en el 2012 y fallecieron 310 mujeres, 25 decesos al mes. Según las estimaciones mundiales todos los años surgen 493, 000 casos nuevos y 274,000 mujeres mueren anualmente.

Nicaragua es a nivel mundial el segundo país, después de Haití con la tasa de incidencia más elevada de cáncer de cuello uterino con 39 casos por 100, 000, un 83\% de los casos tiene lugar en los países en desarrollo donde los programas de detección y prevención no están bien definidos.

El Protocolo de Prevención del Cáncer Cervicouterino que se aplica en Nicaragua consiste en el Tamizaje con inspección Visual con Ácido Acético (IVAA) y Tratamiento con Crioterapia" que fue publicado en el año 2006 y actualizado en 2010, este tiene como objetivo detectar lesiones precancerosas lo que ayuda a determinar el tratamiento para tomar las medidas de prevención ante este tipo de cáncer.

Al detectarse células precancerosas se realiza la prueba de IVAA y posteriormente la colposcopia, ya sea por biopsia o por asa diatérmica, para comprobar la existencia de lesiones celulares 
que no pueden ser observadas a simple vista en la paciente. No obstante existen métodos moleculares, como la Reacción en cadena de la polimerasa (PCR) y sondas de hibridación, que van encaminados a la detección de la presencia y de los genotipos del Virus del Papiloma Humano, ya que se han descrito más de 100 genotipos y 20 de ellos han sido asociados con el cáncer cervical.

\section{Justificación}

Debido a que la cobertura de la Citología Vaginal (PAP) en el país es muy baja (7.7\% en el año 2005), se estima que la dimensión del problema es mucho mayor. En la detección del cáncer cérvico uterino, existe limitada cobertura de lectura de la citología cervical y capacidad de manejo de las lesiones premalignas y malignas que se diagnostican, debido a la escasez de recursos calificados. Solamente se cuenta con un centro de referencia nacional en Managua para el tratamiento de las lesiones malignas e invasivas, mediante técnicas quirúrgicas y cobaltoterapia (MINSA, 2008).

En Nicaragua es de suma importancia aumentar la detección del virus del papiloma mediante una mayor cobertura de toma de PAPs y para un mejor diagnóstico del VPH mediante la Prueba de Reacción en Cadena Polimerasa (PCR), prueba molecular que detecta diez células de virus del papiloma humano entre un millón de células normales, con el objetivo de reducir las tasas de mortalidad de casos de mujeres con cáncer cervicouterino a nivel nacional.

Con este estudio se analizarán las pruebas de detección del cáncer de cérvix asociadas a VPH implementadas en el Hospital Bertha Calderón Roque en mujeres atendidas en consulta externa, las variables que se tomarán en cuenta son las alteraciones histopatológicas detectadas; y los métodos utilizados en el diagnóstico de detección del VPH asociadoal cáncer cervicouterino y por último la edad y procedencia de las pacientes, esto contribuirá en la identificación de las acciones preventivas que hay que tomar y la implementación de un diagnóstico eficaz y específico que pueda garantizar un tratamiento adecuado y temprano para las nicaragüenses.

El virus del papiloma humano (VPH) representa una de las infecciones de transmisión sexual más común, y no obstante, es todavía poco conocida. La familia de VPH cuenta con más de 150 tipos virales que, en relación a su patogenia oncológica, se clasifican en tipos de alto y de bajo riesgo oncológico. El paradigma de los primeros lo constituyen el VPH 16 y 18 y el de los segundos el VPH 6 y 11. Las infecciones por tipos de alto riesgo siguen predominantemente un curso silente, tienden a establecer infecciones persistentes y generan alteraciones citológicas características englobadas mayoritariamente en el grupo de Neoplasia Cervical Grado 1 (CIN 1) o lesiones escamosas 
intraepiteliales de bajo grado (LSIL). En una proporción menor, las infecciones por VPH de alto riesgo pueden inducir lesiones escamosas intraepiteliales de alto grado (CIN 2/3, HSIL) y cáncer cervical (Bosch Francesc Xavier, 2007). Según el Dr. Muñoz, (2014), la gran mayoría de virus que causan carcinomas están asociados a los serotipos 16 y 18, mientras tanto los serotipos 6 y 11 son los que más se relacionan con patologías de tipo condilomatosa.

Los estudios sobre la historia natural de la infección por virus del papiloma humano evidencian que un número importante de hombres y mujeres jóvenes se infectan en las edades de mayor actividad sexual. La mayoría de estas infecciones tiene una resolución espontánea y sin consecuencias. La persistencia del virus del papiloma humano es de un 5\% a un 10\%, en personas luego de los 30 años. Este subgrupo representa el de mayor riesgo para desarrollar lesiones escamosas intraepiteliales de alto grado y cáncer (Dr. Muñoz, 2014).

Las pruebas de diagnóstico sistemático de la infección por el VPH pueden ser clasificadas en microscópicas (citología), visuales (colposcopía), y moleculares (PCR, hibridación, secuenciación, etc). Gutiérrez (2011) afirma: "La citología cervical no es una técnica diagnóstica, las evidencias científicas coinciden en que posee una sensibilidad y especificidad limitada 50-60\% en la detección de lesión NIC II/III, debido a que únicamente reporta si hay algún cambio citopatológico en las células, pero no confirma si la anormalidad citológica es provocada por la presencia de algún genotipo de VPH en particular, específicamente los relacionados con cáncer cervicouterino. Por tanto, aunque una sola prueba negativa de Papanicolaou de alta calidad indique un riesgo bajo de cáncer, por lo general es importante repetir la prueba para poder detectar las lesiones NIC II/III”.

La introducción de las técnicas de biología molecular permitió el resurgir del estudio de papilomavirus, así como el conocimiento de las funciones de los diferentes genes virales, fundamentalmente los oncogenes, además de las propiedades biológicas y bioquímicas del virus. En estudios epidemiológicos se ha podido estimar que de un 2 a un $20 \%$ de la población mundial es portadora oculta del virus del papiloma humano. La mayor parte de los métodos de identificación directa de infección por VPH están basados en la detección del genoma del virus. De manera ideal, un método para la detección del ADN de VPH debe ser capaz de detectar, identificar y cuantificar la presencia de múltiples tipos de VPH. Debe además ser un método que pueda realizarse con facilidad, alta reproducibilidad y elevada especificidad y sensibilidad. A pesar de la gran diversidad de los VPH, su organización genómica es muy conservada (Gutiérrez R. 2011). 
Las lesiones anogenitales incluyen las verrugas genitales (condiloma acuminado, cresta de gallo) que son formaciones carnosas con aspecto de coliflor que aparecen en las zonas húmedas de los genitales. Las verrugas genitales, por lo común, son causadas por los tipos VPH-11 y VPH-16. Estos tipos de VPH también pueden producir verrugas en el cuello del útero, en la vagina, la uretra y el ano. Este virus está relacionado con alteraciones del cuello uterino denominadas displasia cervical y neoplasia intraepitelial cervical (NIC), las cuales se han clasificado en tres grados 1, 2 y 3. La NIC 3 en particular se considera una lesión precancerosa precursora del cáncer cervicouterino.

Es la biopsia en la que se obtiene tejido de la vagina o del cuello del útero y que realizan los ginecólogos ante una prueba de Papanicolaou positiva, para descartar un cáncer de cérvix o de vagina, mediante un colposcopio. La displasia que se observa del cuello uterino se denomina neoplasia intraepitelial cervical (NIC) y se agrupa en tres categorías, basados en el espesor de la invasión por parte de las células escamosas: NIC I: Se caracteriza por estar confinado al 1/3 basal del epitelio cervical. NIC II: confinada a los 2/3 basales del epitelio cervical. NIC III: la displasia es severa y cubre más de los 2/3 de todo el epitelio cervical, en algunos casos incluyendo todo el grosor del revestimiento cervical. Esta lesión puede considerarse como un carcinoma in situ.

Una superficie del cuello uterino rosada y suave es normal. Una biopsia se practica sólo cuando el médico observa tejidos anormales o sospecha su presencia por los resultados anormales de una citología vaginal (Carrillo. A., Lizano. M., Rubí. S. \& Volkow. P, 2009). Finalmente, en la primera de las clasificaciones citológicas de Bethesda se definió una categoría de lesiones citológicas de naturaleza incierta (ASCUS y AGUS - Células Escamosas de Significado Incierto -) en las que la detección de VPH es cercana al $50 \%$ en una lectura citológica experta.

\section{MATERIAL Y MÉTODO}

Se determinaron las pruebas de detección del cáncer cérvico uterino, la frecuencia de cambios celulares del cérvix, sospechosas y asociadas a la presencia del virus del papiloma humano, en mujeres que fueron atendidas en la consulta externa del hospital Bertha Calderón Roque de la ciudad de Managua, el tipo de estudio fue descriptivo de corte transversal, el universo fue de 181 mujeres que se realizaron el examen de citología cervical; la muestra fue de 83 mujeres diagnosticadas con VPH, correspondientes al $45.8 \%$ del total del universo. El tipo de muestreo aplicado fue no probabilístico por conveniencia, ya que se seleccionaron aquellas pacientes que cumplieran con los criterios de inclusión 
siguientes: Pacientes atendidas en la consulta externa, resultados de PAP y expedientes con información completa (exámenes practicados, edad, procedencia), la unidad de análisis fueron las mujeres que presentaron alteraciones cito-morfológicas sospechosas de VPH en el periodo en estudio.

La recolección de la información fue extraída de fuentes secundarias, de los registros del área de patología, y expedientes obtenidos del área de estadística del Hospital Bertha Calderón Roque. Se utilizaron como instrumentos de recolección de datos las fichas epidemiológicas, donde se incluyeron datos generales de las pacientes, métodos diagnósticos utilizados para la detección del virus del papiloma humano, las principales características citológicas e histopatológicas identificadas, los grados de la neoplasia cervical intraepitelial detectados por citología cervical y las etapas clínicas en las cuales evolucionó el cáncer cervicouterino.

Con relación a los aspectos éticos de esta investigación, la información obtenida de las pacientes, se utilizó únicamente como dato de investigación y como dato epidemiológico, omitiendo los nombres para proteger su identidad. Se tuvo acceso al libro de registro por medio del responsable del laboratorio de patología, así mismo los expedientes fueron facilitados por docencia y el área de estadística. Cabe destacar que previamente se presentó una carta solicitando autorización para tener acceso a las fuentes de la información.

\section{ANÁLISIS Y DISCUSIÓN DE LOS RESULTADOS}

Los métodos utilizados para la identificación de alteraciones celulares asociadas al VPH fueron el PAP, colposcopia, biopsia e IVAA para las cuales se obtuvo un total del 100\% exceptuando el último con tan solo un 20\%. El PAP es una prueba que puede detectar cambios morfológicos o células que pueden volverse cancerosas, por lo que su realización resulta de mucha importancia al igual que la colposcopia ya que esta le permite al ginecólogo identificar y tratar problemas comunes del cuello uterino como lo es el cáncer cervical. La biopsia es otro de los métodos de mayor importancia ya que ayuda al estudio del área afectada o con alguna alteración celular. Por otro lado el IVAA a través de la identificación en el cambio de color blanco permite determinar si el resultado de la prueba es positivo o negativo para posibles lesiones precancerosas o cáncer. Sin embargo en el hospital no se realizan pruebas para confirmar o estudiar con mayor certeza si las alteraciones cito- histológicas son debidas al VPH, por lo tanto es necesario detectar la presencia del virus y más aún la identificación de los genotipos de alto riesgo asociados al cáncer cervicouterino. He aquí la importancia de la realización de 
cada uno de estos métodos necesarios para la identificación temprana de cualquiera de las alteraciones existentes y de esta manera prevenir un cáncer causado por el virus del papiloma humano.

En los resultados se obtiene que el $12 \%$ de las mujeres a las que se realizaron PAP presentaron lesión intraepitelial de bajo grado o NIC I, el 14\% se le detectó esta misma alteración por colposcopia seguida del 6\%, para colposcopia y finalmente $6 \%$ para NIC y $11 \%$ para condiloma por biopsia con asa diatérmica. Esto indica que el PAP es menos sensible para NIC I y condiloma es decir que la citología no detecta fácilmente lesiones de bajo grado porque su sensibilidad y especificidad es limitada con apenas un $50 \%$ para la detección de estas anormalidades. Por otro lado la colposcopia al ser un procedimiento exploratorio para observar el epitelio mediante el uso de técnicas de microcopia, permite determinar lesiones de bajo grado con mayor precisión para realizar citología o biopsia, es decir, la colposcopia detecta anormalidades que no se manifiestan en citología.

De igual manera se detectó en caso de condiloma como lesión de bajo grado, un 8\% para PAP, $6 \%$ para colposcopia y finalmente $11 \%$ para biopsia. Al ser la biopsia la que presenta un mayor porcentaje en las mujeres diagnosticadas con condiloma se atribuye que al observar tejidos anormales asociados a la formación de proliferación celular o verrugas, se recomienda la realización de colposcopio y biopsia exocervical y endocervical como prueba de oro para descartar una posible lesión de alto grado que conlleva a cáncer cervicouterino. Este procedimiento se realiza al obtener el resultado de PAP positivo. (Ver figura 1).

La frecuencia de lesiones de alto grado en células escamosas fue detectada por biopsia por asa diatérmica en la que se obtuvo un resultado de 33\%, seguido de un $24 \%$ detectadas por biopsia por colposcopia y un $23 \%$ en el Papanicolaou. Por otro lado las lesiones intraepiteliales de tipo II constituyeron el $19 \%$ para colposcopia y biopsia por asa diatérmica y un 16\% para PAP. Respecto al cáncer in situ los resultados fueron un $7 \%$ para colposcopia, un $6 \%$ para PAP y finalmente un $4 \%$ para biopsia.

\section{Lesiones de bajo grado en células escamosas asociadas al VPH}




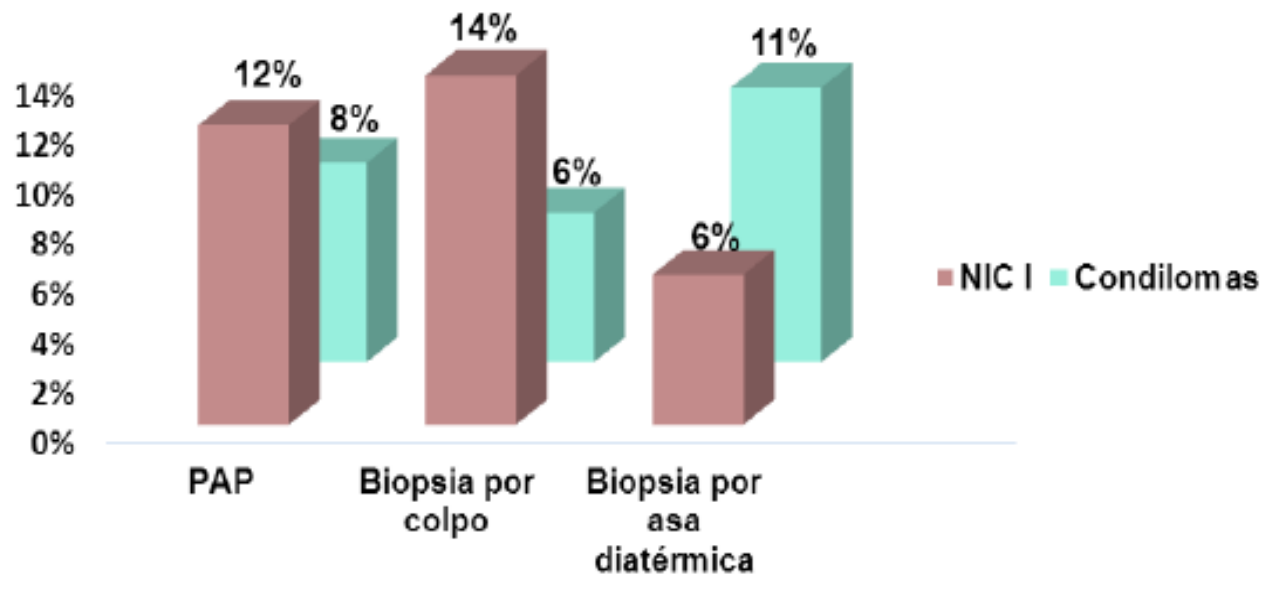

Figura 1. Frecuencia de lesiones de bajo grado en células escamosas asociadas al Virus del Papiloma Humano (VPH) en pacientes atendidas en consulta externa en el Hospital Bertha Calderón Roque en el periodo Enero-Julio 2013. Fuente: tabla no 1.

Las lesiones intraepiteliales de tipo III (NIC III) se detectaron con más frecuencia en los tres métodos diagnósticos. En el caso de biopsia por asa diatérmica con un $33 \%$ seguido de un $24 \%$ detectadas por biopsia por colposcopia y un $23 \%$ en el Papanicolaou. Comparando los métodos del PAP y colposcopia la detección de dicha alteración tuvo una diferencia de apenas el 1\%.

Con respecto a la Biopsia por asa diatérmica se obtuvo un porcentaje mayor en relación a los otros métodos debido a su alta precisión y sencillez por lo que se utiliza en el tratamiento.

Por otro lado las Neoplasia Intracervical II constituyeron el 19\% para colposcopia y biopsia por asa diatérmica y un $16 \%$ para PAP. La colposcopía se encontró en mayor porcentaje debido a que es uno de los métodos exploratorios más efectivos ya que permite la observación directa del cérvix in vivo permitiendo definir el grado exacto de la lesión, evaluar su extensión y tomar muestras del tejido. (ver figura 2).

La frecuencia de células escamosas atípicas que se asocian al VPH con los diferentes métodos de diagnósticos en el PAP se obtuvo un 22\% para ASCUS lo que significa que hay leves cambios anormales en las células del cuello del útero no necesariamente causado por VPH lo cual depende de los factores de riesgos, si no los presenta el médico recomienda una citología para descartar VPH, si el resultado de esta citología es repetida con atipia indeterminada o presencia de lesión asociada a alto grado, se debe practicar métodos complementarios como colposcopia o biopsia. Para ASC-H se obtuvo 
un $7 \%$ lo que indica que las células del revestimiento de la parte exterior de cuello uterino son anormales el cual se interpreta como lesión precancerosa y para descartar este diagnóstico se le realizara colposcopia y biopsia, si el resultado conlleva a la misma atipia, con ayuda de estos métodos se puede detener el progreso de la infección.

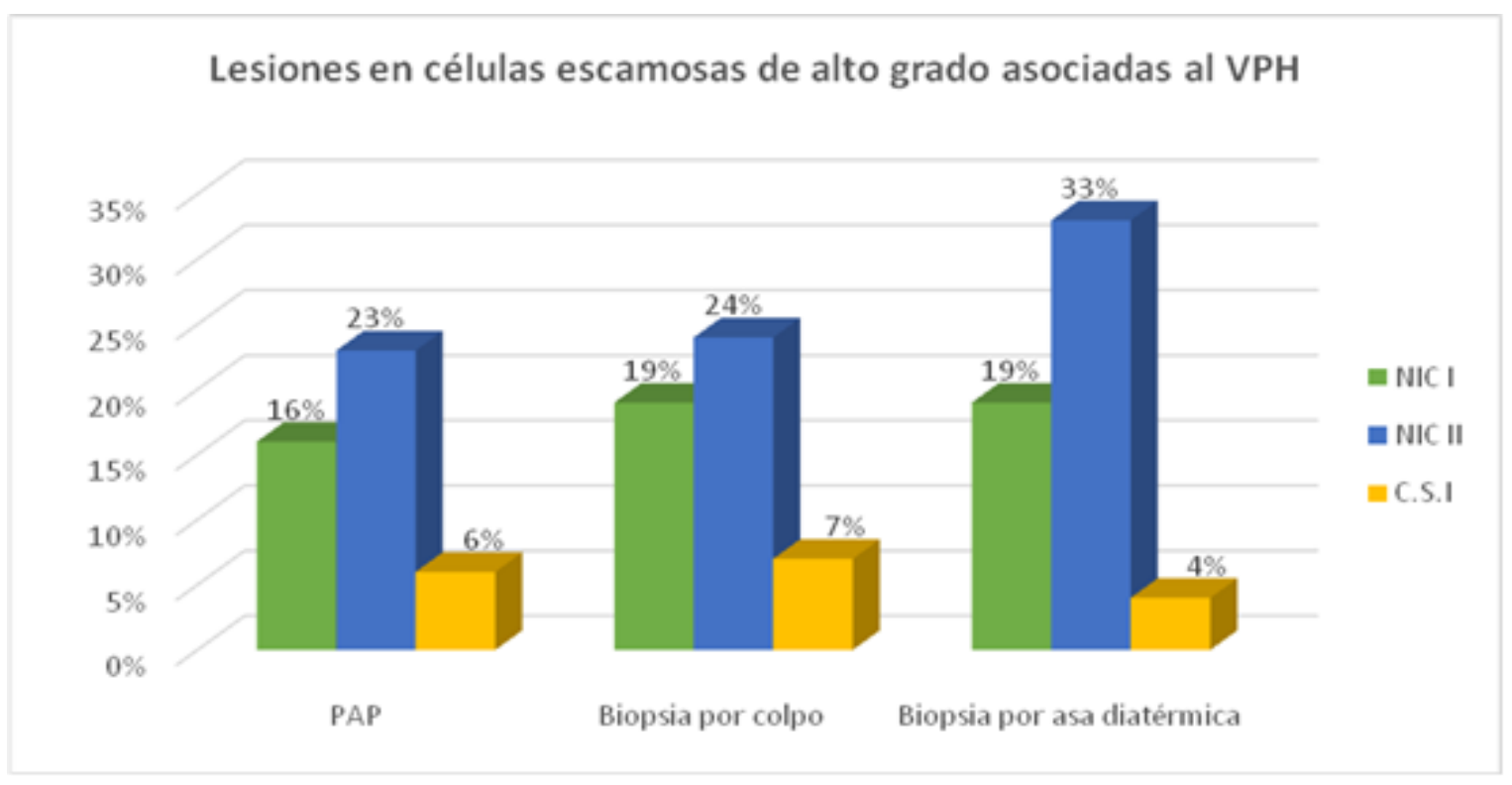

Figura 2. Frecuencia de lesiones en células escamosas de alto grado asociadas al Virus del Papiloma Humano (VPH) en pacientes atendidas en consulta externa en el Hospital Bertha Calderón Roque en el periodo Enero-Julio 2013.

Con respecto al diagnóstico obtenido mediante biopsia por colposcopía, ASCUS presentó 19\% y ASC-H 6\% por lo que este método es más sensible que el diagnóstico por PAP, este es el método de referencia para medir la verdadera prevalencia de la enfermedad precancerosa o precozmente maligna dirigida sobre las zonas sospechosas y por lo tanto, es la técnica de referencia para comparar el estudio del VPH con la repetición de la citología, ya que esta detecta un número considerable de anormalidades celulares que pueden carecer de significado clínico. Así mismo, se reflejó que biopsia por asa diatérmica obtuvo un 20\% para ASCUS y 6\% para ASC-H, este es un procedimiento para el diagnóstico cuando la prueba del PAP es anormal, por lo que es más sensible. Permite eliminar con gran precisión el área afectada en el cérvix, por lo que suele ser suficiente para establecer el diagnóstico en casos de lesiones pequeñas por lo que si se diagnostica lesiones pre- 
malignas o precancerosa como ASCUS Y ASC-H este método puede servir simultáneamente terapéutico. (Ver figura 3).

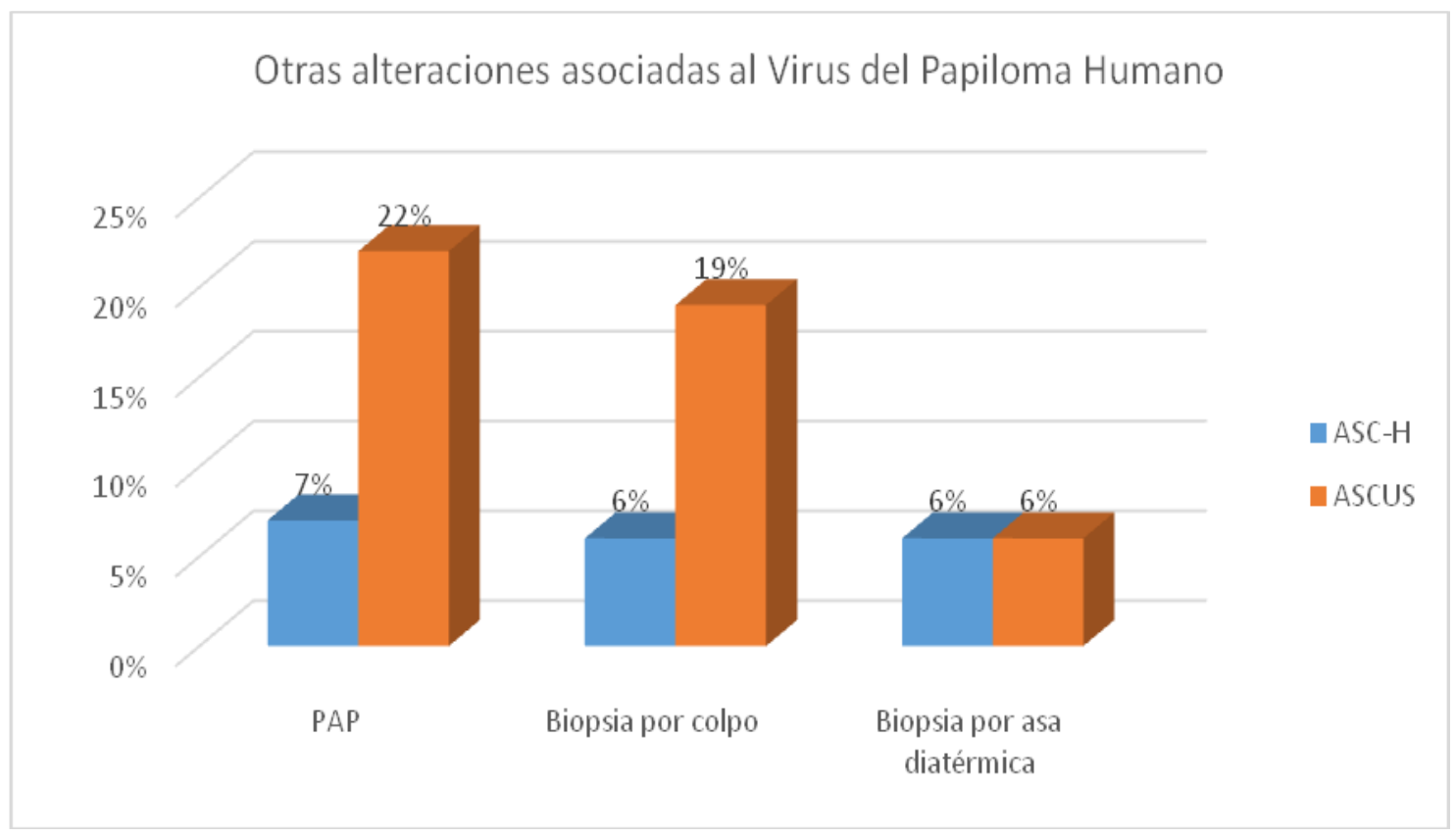

Gráfica 3. Frecuencia de otras alteraciones asociadas al Virus del Papiloma Humano (VPH) diagnosticadas por PAP, Colposcopia y Biopsia por asa diatérmica en mujeres atendidas en consulta externa en el Hospital Bertha Calderón Roque en el periodo, Enero - Julio 2013.

\section{CONCLUSIONES}

Los métodos diagnósticos utilizados para la detección del cáncer cérvical asociados al virus de Papiloma Humano fueron citológicos (PAP) y biopsia por conización mediante asa diatérmica, colposcopía y la inspección visual con ácido acético se le realizó al 20\% de las mujeres en estudio, no se realizan pruebas de detección de los componentes del virus.

Los mayores porcentajes en detección de las alteraciones histopatológicas fueron detectados mediante Biopsia por colposcopia para lesiones de bajo grado o NIC I y biopsia por asa diatérmica para condilomas.

Para las lesiones escamosas de alto grado, se obtuvo un 33\% para NIC III mediante biopsia por asa diatérmica. ASCUS en un $22 \%$ a través de PAP y un $7 \%$ para ASC-H por medio del mismo método.

Las edades predominantes de las pacientes en estudio, estuvieron comprendidas entre los 19 a los 48 años correspondientes a un $70 \%$. 


\section{REFERENCIAS}

Alianza para la Prevención del Cáncer Cervicouterino (SF). Recuperado de http://www.alliancecxca.org

Carrillo. A., Lizano. M., Rubí. S. y Volkow. P. (2009). GynecolOncol. High prevalence of oncogenic human papillomavirus in the genital tract of women with human immunodeficiency virus.

Dabancens. A., Ojeda. F y Prado. R. (2004). MEDWAVE - Ciencia. Facultad de Medicina, Universidad de Chile. Recuperado de http://www.medwave.cl/ciencia/15

Egea. A. y Molina. C. (2004). El virus del papiloma humano (HPV), agente viral importante precursor de la mayoría de las displasias o cáncer cervical. Recuperado de http://www.redalyc.org/pdf/817/8171900

García Saiz Alfredo; et al. (2007) Centro Nacional de Microbiología. Instituto de Salud Carlos III. virus del papiloma humano situación actual, vacunas - aepcc, www.aepcc.org/download/.../

Gutiérrez. R. (2011).Utilidad de las técnicas moleculares de detección de VPH en el control y prevención del cáncer cervicouterino. Madrid-España. Recuperado de: http://www.medigraphic.com/pdfs/arc hivostgi/tgi-2011/tgil15c.pdf. 5:17

Minsa (2008), Estrategias Nacional de salud sexual y reproductiva, ISBN: 978-99924-911-7-1

Muñoz.N. (2000).Human papillomavirus and cancer. The epidemiological evidence. Organización panamericana de la salud (OPS).(2013). Aplicación de ácido acético IVAA. Recuperado de: http://www.paho.org/hq/index.php?option $=$ com_docman\&task $=$ doc_view\&gid=18721\&Itemid $=$ .p. 8

Rachel. L. (2006). Condom Use and the Risk of Genital Human Papillomavirus Infection in Young Women.New EnglandJournal of Medicine, 354 (25).

Saavedra. L., Saberon. L. (2006). Unidad de investigación biomédica en cáncer- UNAM-INCAN. Cáncer cervicouterino y el virus del papiloma humano: la historia que no termina. P.31-55

Vivero. D., M. (2013). Manual de prácticas de laboratorio, técnicas citológicas. Facultad de Bioanálisis, universidad de veracruzana. Recuperado de http://es.scribd.com/doc/17536/TECNIC AS-citologicas 